\title{
Occurrence of virulence factors and antimicrobial resistance in Pasteurella multocida strains isolated from slaughter cattle in Iran
}

\author{
Faham Khamesipour ${ }^{1}$, Hassan Momtaz ${ }^{2 *}$ and Morteza Azhdary Mamoreh ${ }^{3}$ \\ ${ }^{\prime}$ Young Researchers and Elite Club, Shahrekord Branch, Islamic Azad University, Shahrekord, Iran \\ ${ }^{2}$ Department of Microbiology, Faculty of Veterinary Medicine, Shahrekord Branch, Islamic Azad University, Shahrekord, Iran \\ ${ }^{3}$ Faculty of Veterinary Medicine, Shahrekord Branch, Islamic Azad University, Shahrekord, Iran
}

\section{Edited by: \\ Christina Maria Joseph Elisabeth \\ Vandenbroucke-Grauls, VU \\ University Medical Center, \\ Netherlands}

\section{Reviewed by:}

Amanda L. Lewis, Washington University School of Medicine, USA Alasdair Cook, University of Surrey School of Veterinary Medicine, UK

*Correspondence:

Hassan Momtaz, Department of Microbiology, Faculty of Veterinary Medicine, Shahrekord Branch, Islamic Azad University, PO Box 166, Shahrekord, Iran e-mail: hamomtaz@yahoo.com; hamomtaz@iaushk.ac.ir
A total of 30 Pasteurella multocida strains isolated from 333 pneumonic and apparently health slaughter cattle were examined for capsule biosynthesis genes and 23 virulence-associated genes by polymerase chain reaction (PCR). The disc diffusion technique was used to determine antimicrobial resistance profiles among the isolates. Of the isolates, 23 belonged to capsular type A, 5 to capsular type D and two isolates were untypeable. The distribution of the capsular types in pneumonic lungs and in apparently health lungs was statistically similar. All virulence genes tested were detected among the isolates derived from pneumonic lungs; whereas isolates derived from apparently health lungs carried 16 of the 23 genes. The frequently detected genes among isolates from pneumonic lungs were exbD, hgbA, hgbB, ompA, ompH, oma87, and sodC; whereas $\operatorname{tad} D$, tox $A$, and pmHAS genes occurred less frequently. Most of the adhesins and superoxide dismutases; and all of the iron acquisition and protectin proteins occurred at significantly $(p \leq 0.05)$ higher frequencies in isolates from pneumonic lungs. Isolates from apparently healthy lungs didn't carry the following genes; hsf-1, hsf-2, tadD, toxA, nanB, nanH, and pmHAS. One adhesion (hsf-1) and two iron acquisition (exbD and tonB) genes occurred at significantly $(p \leq 0.05)$ higher frequencies among capA isolates. All the P. multocida isolates were susceptible to ciprofloxacin, co-trimoxazole, doxycycline, enrofloxacin, nitrofurantoin, and tetracyclines. Different proportions of the isolates were however resistant to ampicillin, amoxicillin, erythromycin, lincomycin, penicillin, rifampin, streptomycin, and florfenicol. Our results reveal presence of virulence factors (VFs) in P. multocida strains isolated from symptomatic and asymptomatic bovids. A higher frequency of the factors among isolates from symptomatic study animals may suggest their role in pathogenesis of $P$. multocida-associated bovine respiratory disease (BRD). The results further reveal occurrence of antimicrobial resistance among some isolates. Control strategies for this pathogen, which could include development of an effective vaccine, are warranted so as to mitigate the social and economic consequences attributable to natural infections with this bacterium.

Keywords: Pasteurella multocida, virulence factors, antimicrobial resistance, cattle, Iran

\section{INTRODUCTION}

Cattle rearing is one of the important sources of income in Iran, involving both dairy and beef breeds. The sector faces a number of constraints ranging from limited feed resources to diseases. Of the diseases, those caused by infectious agents are of great importance which include bacteria and viruses affecting the respiratory system (Hemmatzadeh et al., 2001; Haji Hajikolaei and Seyfi Abad Shapouri, 2007; Sakhaee et al., 2009). The most important bacteria that play a role in pneumonia include: Mannheimia haemolytica, Pasteurella multocida, and Haemophilus somnus pneumonia, which presence of these bacteria in pneumonia lesions of slaughtered cattle around Iran have also been reported (Haji Hajikolaei et al., 2010).
Bovine respiratory disease (BRD) is a significant cause of morbidity and mortality among beef cattle in the world (Dagleish et al., 2010; Hotchkiss et al., 2010; Portis et al., 2012). Among others, Pasteurella multocida has been identified as a major bacterial etiologic agent for this disease (Confer, 2009; Griffin et al., 2010). It is a zoonotic Gram negative bacterium responsible for a range of infections in domestic animals causing substantial economic losses (Steen et al., 2010). The organism causes fowl cholera in domestic and wild birds, bronchopneumonia and hemorrhagic septicemia in bovids, atrophic rhinitis in porcines and snuffles in rabbits (Mannheim, 1984; Hunt et al., 2000). Most human infections with P. multocida result from dog and cat bites, but infections through 
the respiratory tract may also occur (Hubbert and Rosen, 1970).

Several host and pathogen-specific attributes do determine the outcome of infections caused by P. multocida (Verma et al., 2013). Of the pathogen factors important ones include the capsular and virulence-associated genes (Katsuda et al., 2013). These virulence factors (VFs) and outer membrane proteins are important for pathogenesis, functionality, protective immunity and vaccine development against P. multocida infections (Harper et al., 2006; Hatfaludi et al., 2010). Based on capsular antigens, P. multocida strains are differentiated into five serogroups i.e., type A causing fowl cholera pathogen and bovine shipping fever, type B causing hemorrhagic fever in ungulates, type $\mathrm{D}$ causing atrophic rhinitis in swine, type E, an African serotype, infecting cattle and buffalo; and type F also causing fowl cholera (Carter, 1955, 1961, 1967; Rimler and Rhoades, 1987). Virulence associated genes described for $P$. multocida isolates and their examples include adherence and colonization factors ( $p t f A, f i m A, h s f-1, h s f-2, p f h A$, and tadD), iron-regulated and acquisition proteins $(\operatorname{exb} B, \operatorname{exbD}$, ton $B, h g b A$, $h g b B$, and Fur), extracellular enzymes such as neuraminidase ( $n a n B$ and $n a n H)$, hyaluronidase ( $p m H A S$ ) and superoxide dismutases ( $\operatorname{sod} a, \operatorname{sod} C$, and $t b p A)$, toxins (toxA), lipopolysaccharides (LPS), capsule and a variety of outer membrane proteins such as protectins (ompA, omph, oma87, and $p l p B$ ) (Katoch et al., 2014).

Increased use of antibiotics in modern animal production has been associated with emergence of antimicrobial resistant bacteria with potential for transfer of resistance from animals to humans (Witte, 1998). As a result, antimicrobial resistance among bacterial pathogens has of recent become a big problem in both the veterinary and human medicine fields (Levy, 1998; Caprioli et al., 2000; Kehrenberg et al., 2001; White et al., 2002; Shea, 2003). The implication of the problem is increased treatment cost, prolonged illness due to treatment failure and sometimes death (Kelly et al., 2004).

The present study was conducted with the aim to detect the occurrence of VFs in P. multocida isolated from pneumonic and apparently health lungs of slaughter cattle in Iran. It was also to determine the occurrence of antimicrobial resistance among the isolates.

\section{MATERIALS AND METHODS SAMPLE COLLECTION}

A total of 333 samples, from both pneumonic (219) and apparently healthy (114) lungs, were collected randomly from slaughter cattle in an industrial abattoir in Shahrekord province during the period of September 2013 to March 2014. The abattoir receives cattle from different herds within and outside the province. For the purpose of this study pneumonic lungs referred to those lungs with gross lesions such as consolidation, fibrin deposition on the pleura, pleurisy, and/or adhesion; and apparently healthy lungs was used to describe those lungs without gross lesions. A simple random procedure was used to select pre-identified pneumonic and apparently health lungs. Random numbers were generated in Microsoft excel ${ }^{\circledR}$. Specimens were obtained aseptically using a sterile scalpel while taking precautions to prevent surface contamination. Following collection the samples were conveyed to the microbiology laboratory in special ice-filled containers within $6 \mathrm{~h}$ of sampling.

\section{P. MULTOCIDA SCREENING}

Isolation of $P$. multocida was done using techniques described previously by other authors (Songer and Post, 2005). Briefly, swabs were obtained from the collected samples and were plated on tryptic soy agar (Difco, Detroit, MI) containing $10 \mu \mathrm{g} / \mathrm{ml}$ NAD (Sigma, St. Louis, MO) and 5\% bovine serum, MacConkey agar, and blood agar ( $5 \%$ fresh sheep blood). All plates were incubated at $37^{\circ} \mathrm{C}$ in air for a minimum of $48 \mathrm{~h}$.

\section{IDENTIFICATION OF ISOLATES}

Preliminary identification of $P$. multocida isolates was carried out according to standard biochemical tests as described earlier (Songer and Post, 2005). The isolates were gram-negative coccobacilli and were indole, catalase and oxidase-positive. But, citrate, Methyl red (MR), Vogaes-Proskauer (VP), and gelatin liquefaction negative. They don't grow on MacConkey agar and do not show hemolysis on blood agar. Confirmation of the isolates was done by polymerase chain reaction (PCR) assay with primers specific for the amplification of the KMT1 gene, adopting the methodology previously described by Townsend et al. (1998). All confirmed isolates of $P$. multocida were subsequently characterized by capsular serotyping using PCR. Primers for amplification of hyaD-hyaC and DcbF genes were used for detection of capsular type A and capsular type D, respectively (Table 1). P. multocida isolates which didn't yield bands on PCR when the two primers were used were classified as untyped. Following confirmation and characterization all isolates were freeze-dried and kept at $-20^{\circ} \mathrm{C}$.

\section{DETECTION OF VIRULENCE GENES}

The virulence genes of $P$. multocida isolates were detected by PCR. They included adhesins ( $p t f A, f i m A, h s f-1, h s f-2, p f h A$, and tadD),

Table 1 | Primers used for the detection of serogroups in strains of $P$ multocida.

\begin{tabular}{|c|c|c|c|c|c|c|}
\hline Serogroup & Gene & $\begin{array}{l}\text { Primer } \\
\text { name }\end{array}$ & Primer sequence $\left(5^{\prime}-3^{\prime}\right)$ & Amplic size (bp) & Anneal. Temp $\left({ }^{\circ} \mathrm{C}\right)$ & Reference \\
\hline All & KMT1 & $\begin{array}{l}\text { KMT1T7 } \\
\text { KMT1SP6 }\end{array}$ & $\begin{array}{l}\text { ATCCGCTATTTACCCAGTGG } \\
\text { GCTGTAAACGAACTCGCCAC }\end{array}$ & 460 & 55 & Townsend et al., 1998 \\
\hline Capsular type A & hyaD-hyaC & $\begin{array}{l}\text { CAPA-F } \\
\text { CAPA-R }\end{array}$ & $\begin{array}{l}\text { CATTTATCCAAGCTCCACC } \\
\text { GCCCGAGAGTTTCAATCC }\end{array}$ & 760 & 55 & \\
\hline Capsular type D & DcbF & $\begin{array}{l}\text { CAPD-F } \\
\text { CAPD-R }\end{array}$ & $\begin{array}{l}\text { TTACAAAAGAAAGACTAGGAGCCC } \\
\text { САTCTACCCACTCAACCATATCAG }\end{array}$ & 657 & 55 & \\
\hline
\end{tabular}


toxin $(\operatorname{tox} A)$, iron acquisition (exbB, exbD, ton $B, h g b A, h g b B$, and Fur), sialidases (nanB and nanH), hyaluronidase (pmHAS), protectins (ompA, omph, oma87, and $p l p B)$ and superoxide dismutases (soda, sodC, and tbpA) (Table 2). The base sequences and the predicted sizes of the amplified products for the specific oligonucleotide primers used in detection of the genes in this study are shown in Table 3. The bacterial lysates used as templates for the PCR were prepared as follows. A loopful of bacteria from a fresh overnight culture on a tryptic soy agar plate was resuspended homogeneously in $200 \mu \mathrm{l}$ of sterile water, and the mixture was boiled at $100^{\circ} \mathrm{C}$ for $5 \mathrm{~min}$ to release the DNA and centrifuged. A $4 \mu \mathrm{l}$ volume of the supernatant was used as a template for each $25 \mu \mathrm{l}$ PCR mixture. The amplified products were analyzed in $1 \%$ agarose gels by electrophoresis, and the results were recorded with a gel documentation system. All tests were repeated three times in parallel with the relevant positive ( $P$. $m u l$ tocida strains ATCC 15742, ATCC 12945, and ATCC 12946) and negative (distilled water) controls. Discrepant results for each VF

Table 2 | Tested virulence-associated genes in strains of $P$ multocida.

\section{Gene function and gene Description}

\begin{tabular}{|c|c|}
\hline \multicolumn{2}{|c|}{ ADHESINS } \\
\hline ptfA & Type 4 fimbriae \\
\hline fimA & Fimbriae (from Pm70) \\
\hline hsf-1 & Autotransporter adhesion (from Pm70) \\
\hline hsf-2 & Autotransporter adhesion (from Pm70) \\
\hline pfhA & Filamentous hemagglutinin \\
\hline tadD & Putative non-specific tight adherence protein $\mathrm{D}$ \\
\hline toxA & Dermonecrotic toxin \\
\hline exbB & $\begin{array}{l}\text { Accessory protein Ton-dependent transport of } \\
\text { iron compounds }\end{array}$ \\
\hline exbD & $\begin{array}{l}\text { Accessory protein Ton-dependent transport of } \\
\text { iron compound }\end{array}$ \\
\hline tonB & $\begin{array}{l}\text { Iron transporters, transport ferric-siderophore } \\
\text { complexes }\end{array}$ \\
\hline hgbA & A hemoglobin-binding protein \\
\hline hgbB & B hemoglobin-iron uptake \\
\hline Fur & Ferric uptake regulation protein \\
\hline \multicolumn{2}{|c|}{ SIALIDASES nanB } \\
\hline nanB & $\begin{array}{l}\text { Outer membrane-associated proteins, an } \\
\text { autotransporter protein }\end{array}$ \\
\hline nanH & $\begin{array}{l}\text { Outer membrane-associated proteins, small } \\
\text { sialidases }\end{array}$ \\
\hline \multicolumn{2}{|c|}{ HYALURONIDASE } \\
\hline pmHAS & Hyaluronan synthase \\
\hline \multicolumn{2}{|c|}{ SUPEROXIDE DISMUTASE } \\
\hline sodA & Superoxide dismutase \\
\hline $\operatorname{sodC}$ & Superoxide dismutase \\
\hline tbpA & Superoxide dismutase \\
\hline \multicolumn{2}{|c|}{ PROTECTINS } \\
\hline ompA & Outer membrane protein A \\
\hline $\mathrm{ompH}$ & Outer membrane protein $\mathrm{H}$ \\
\hline oma87 & Outer membrane protein 87 \\
\hline plpB & Lipoprotein B \\
\hline
\end{tabular}

were investigated further, and samples were sequenced for gene verification.

\section{ANTIMICROBIAL RESISTANCE TEST}

Antimicrobial resistance profiles of the isolates to 20 antimicrobial agents were determined by the disc diffusion method on Muller Hinton agar with 5\% blood (Carter and Subronto, 1978). The plates were inoculated with a cotton swab dipped into a $0.5 \mathrm{McF}$ arland standard suspension of each isolates, according to the procedures outline in NCCLS (NCCLS, 2008). Then, the plates were incubated at $37^{\circ} \mathrm{C}$ for $24 \mathrm{~h}$. The inhibition zones around each disc were measured and interpretation of results made according to the guidelines provided by manufacturers (Pattan-Teb, Tehran, Iran) and those provided by NCCLS (2008). The results were interpreted as resistant (R), intermediate (I), and susceptible (S).

\section{STATISTICAL DATA ANALYSIS}

Data analysis was performed in SPSS software version 12.0 (SPSS Inc., Chicago, IL). Descriptive statistics were computed to determine the proportions of the different VFs among the isolates; and proportions of isolates resistant to different antimicrobial agents. Chi square test adopted for determination of statistical significance of differences between the proportions.

\section{RESULTS}

\section{PREVALENCE OF P. MULTOCIDA IN COLLECTED SAMPLES}

The prevalence of $P$. multocida in collected lung samples is indicated in Table 4. Overall 9.0\% (30/333) of the sampled cattle were infected with the organism. The frequency of infection with the organism was higher in pneumonic lungs than in apparently health lungs and the difference was statistically significant at $p \leq 0.05$.

\section{DISTRIBUTION OF VFs ACCORDING TO CAPSULAR SEROTYPES}

Two capsular types (A and D) were detected among 28 of the 30 isolates obtained as seen in Tables 5, 6. The majority $(76.7 \%)$ of the isolates were of capsular type A. The distribution of the capsular types in pneumonic lungs and in apparently health lungs (Table 5) didn't show any statistically significant difference. The distribution of capsular serotypes for each individual isolate is displayed in Table 6.

\section{DISTRIBUTION OF VFs ACCORDING TO ASSOCIATED VF GENES}

All isolates from pneumonic lungs harbored at least one virulence gene as displayed in Table 7. Table 8 shows the distribution of virulence genes by capsular serotypes. The detected virulence genes for each isolate obtained in this study is presented in Table 6. Most of the adhesins and superoxide dismutases; and all of the iron acquisition and protectin proteins occurred at significantly $(p \leq 0.05)$ higher frequencies in isolates from pneumonic lungs. One adhesion ( $h s f-1)$ and two iron acquisition (exbD and ton $B$ ) genes occurred at significantly $(p \leq 0.05)$ higher frequencies among capA isolates. 
Table 3 | Primers used for the detection of virulence-associated genes in strains of $\boldsymbol{P}$ multocida.

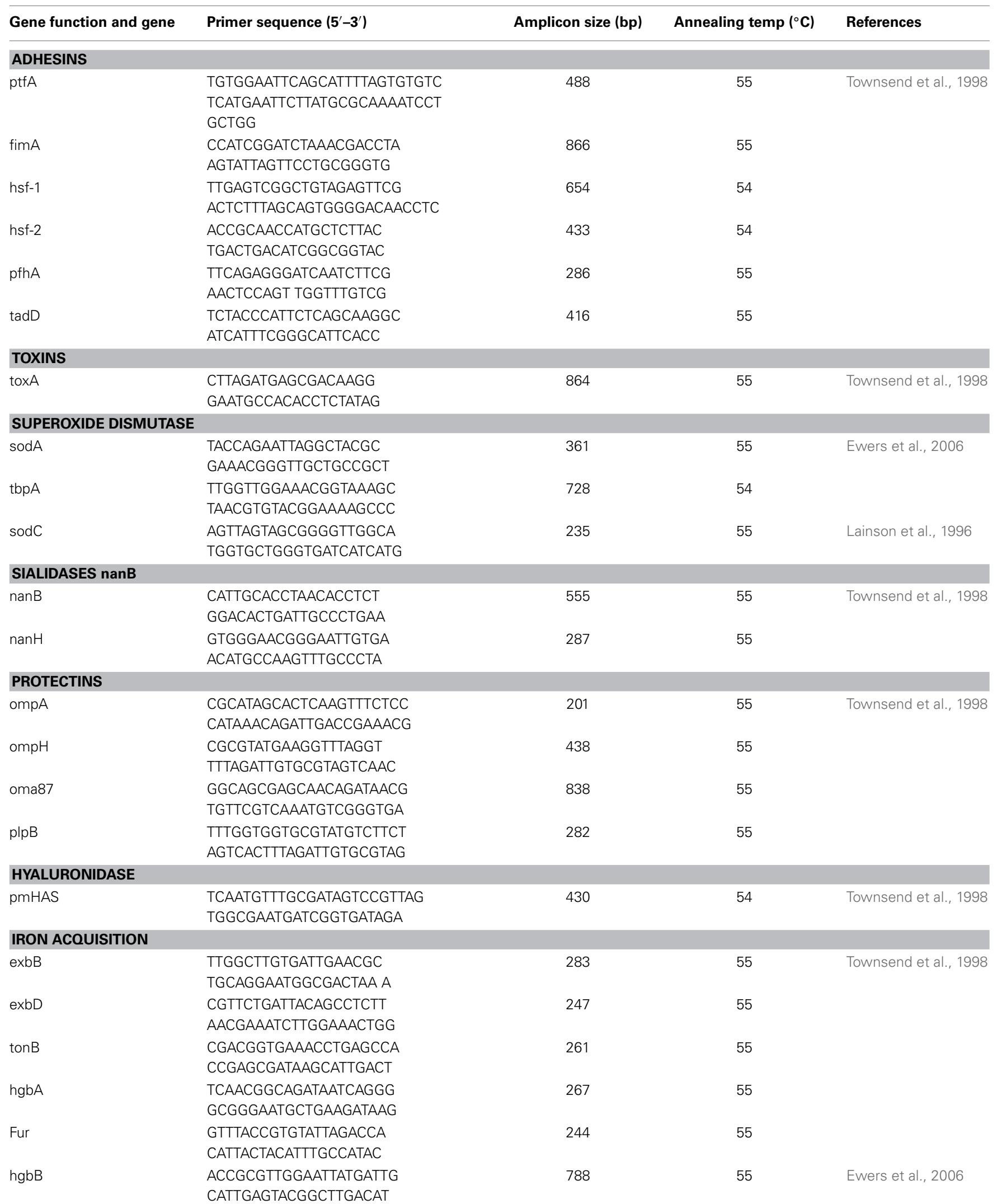


Table 4 | Prevalence of $P$ multocida in collected cattle lung samples.

\begin{tabular}{lcc}
\hline Lung samples & Number of samples & Number of positive samples \\
\hline Pneumonic lungs & 219 & $25(11.4 \%)$ \\
Healthy lungs & 114 & $5(4.4 \%)$ \\
Total & 333 & $30(9.0 \%)$ \\
\hline
\end{tabular}

Table 5 | Distribution of capsular serotypes among the isolates.

\begin{tabular}{lccc}
$\begin{array}{l}\text { Capsular } \\
\text { types }\end{array}$ & $\begin{array}{c}\text { Overall } \\
\text { prevalence } \\
(\boldsymbol{n}=\mathbf{3 0 )}\end{array}$ & $\begin{array}{c}\text { Pneumonic lung } \\
\text { isolates } \\
(\boldsymbol{n}=\mathbf{2 5})\end{array}$ & $\begin{array}{c}\text { Apparently healthy } \\
\text { lung isolates } \\
(\boldsymbol{n}=\mathbf{5})\end{array}$ \\
\hline Type A & $23(76.7 \%)$ & $18(72.0 \%)$ & $5(100.0 \%)$ \\
Type D & $5(16.7 \%)$ & $5(20.0 \%)$ & - \\
Untyped & $2(6.7 \%)$ & $2(8.0 \%)$ & - \\
\hline
\end{tabular}

\section{ANTIMICROBIAL RESISTANCE AMONG THE ISOLATES}

Antimicrobial resistance profiles of $P$. multocida isolates obtained in this study are displayed in Table 9. All the isolates were susceptible to ciprofloxacin, co-trimoxazole, doxycycline, enrofloxacin, nitrofurantoin, and tetracyclines. Resistance to ampicillin, lincomycin, penicillin, rifampin, streptomycin, amoxicillin, erythromycin, and florfenicol was observed at different frequencies.

\section{DISCUSSION}

VFs play a key role in disease production by bacterial pathogens (Nanduri et al., 2009). Among others, their functions include competence, adherence, synthesis, and export of capsules; and evasion of host immune responses (Nanduri et al., 2009). In the present study the factors have been detected in $P$. multocida isolated from the lungs of slaughter cattle. The higher frequency of the factors among isolates from pneumonic lungs suggests the role of these factors in disease occurrence. It was pointed out that virulence gene occurrence in $P$. multocida has a strong positive association with the outcome of infection with the organism in cattle (Katsuda et al., 2013). On the other hand occurrence of the factors in apparently healthy lungs could possibly indicate early infection or contained infection which couldn't lead to disease. It was previously reported that this facultative anaerobic bacterium is commonly found in clinically healthy calves (Lainson et al., 2013).

In this study capsular types A and D were detected using PCR among the obtained $P$. multocida isolates. A small proportion $(6.7 \% ; 2 / 30)$ of $P$. multocida strains were untypeable, a similar observation to what was reported by Arumugam et al. (2011). Capsular type A was predominant among the strains accounting for $76.6 \%$. Our observation is similar to a finding by Katsuda et al. (2013) who also detected capsular types A and D among cattle derived P. multocida isolates; with type A occurring at higher frequency. A higher frequency of capsular type A among cattle derived $P$. multocida isolates has also been reported in a study conducted earlier by Davies et al. (2004) who found that $99.3 \%$ of bovine $P$. multocida strains $(n=153)$ were of this capsular type. P. multocida isolates of serotype A are common in bovids occurring as normal flora in the nasopharynx; or as causes of disease including BRD and hemorraghic septicemia (Ewers et al., 2004; Dabo et al., 2007). The capsular type A is also most frequently described for rabbits (Ewers et al., 2006) and pigs (García et al., 2011).

Of the protectins; OmpA and oma87 were the most frequently detected genes particularly in the isolates from pneumonic lungs. Slightly higher frequencies of the two genes were noted for isolates of the capA serogroup than those belonging to the capD serogroup. The OmpA gene has a significant role in stabilizing the cell envelope structure by providing physical linkage between the outer membrane and peptidoglycan (Katoch et al., 2014). It mediates $P$. multocida host cells interaction through heparin and/or fibronectin binding and thus acts as an important invasive molecule which could determine the outcome of infection with the organism (Katoch et al., 2014).

The type 4 fimbria (ptfA gene) was described in $92.0 \%$ of the isolates tested in the current study. The gene plays a key role of fixing bacterial pathogens on the surface of the epithelial cells of hosts, a phenomenon which is more common in rabbits (Ewers et al., 2006). Consequently a study conducted on rabbits described a high prevalence of the ptfA gene $(93.4 \% ; 43 / 46)$.

Presence of adhesins on the bacterial surface is usually linked to virulence as these proteins are known to play a crucial role in facilitating host invasion and colonization (Kline et al., 2009). Studies by Ewers et al. (2000) and Tang et al. (2009) have demonstrated that, of the adhesins; fimA, hsf-2, and ptfA are of frequent occurrence among pathogenic isolates of $P$. multocida. In the current study the three adhesins were demonstrated at higher frequencies than others in both capA and capD serogroup isolates. On the other hand, gene tadD was the least frequently detected adhesin among $P$. multocida, occurring only in $48.0 \%$ of the isolates $(n=30)$. In these organisms the gene is known to be a putative non-specific tight adherence protein D (May et al., 2001). A more or less similar low frequency $(43.3 \%$; 100/233) of tadD was described in a field study involving pigs (Tang et al., 2009). A work on rabbits, however, observed a higher frequency $(91.3 \%$; 42/46) of this gene among $P$. multocida strains.

It is noteworthy that the dermonecrotoxin encoding toxA was the least frequently detected gene among the isolates; demonstrated only in those of capsular type A obtained from pneumonic lungs. Some other researchers indicated that this particular gene is more frequently expressed by strains of serogroup D and is responsible for the clinical symptoms associated with atrophic rhinitis in porcines (Harper et al., 2006; Ferreira et al., 2012). The observation in the current study could be attributed to the small sample size of capsular type D isolates. In a study conducted earlier the gene was detected in P. multocida isolates from avians, swine, shoats and cattle; but was only associated with disease in pigs (Ewers et al., 2006). Pullinger et al. (2004) points out that the toxA gene is not inserted into the bacterial chromosome but in a lysogenic bacteriophage that infects the agent.

The $t b p A$ encoding gene is known to be of common occurrence among ruminant $P$. multocida strains (Ewers et al., 2006; Atashpaz et al., 2009). Its prevalence was however relatively low when compared to other superoxide dismutases ( $\operatorname{sodA}$ and sodC) tested in this study. Ferreira et al. (2012) found a low frequency (8.6\%; 
Table 6 | Capsular types and virulence genes detected among $P$. multocida isolates obtained from cattle lungs in Iran.

\begin{tabular}{lll}
\hline Strain ID & Capsule type & Virulence genes \\
\hline 1 & Type A & $\begin{array}{l}p t f A, f i m A, ~ h s f-1, \operatorname{ton} B, h g b A, \text { hgbB, Fur, } \\
\text { nanB, nanH, pmHAS, ompA, oomph, plpB, } \\
\end{array}$ \\
& & soda, sodC
\end{tabular}

2 Type A ptfA, fimA, hsf-1, exbD, tonB, hgbA, hgbB, Fur, nanB, nanH, pmHAS, ompA, oomph, oma87, plpB, soda, sodC

\begin{tabular}{ll}
\hline Type A & $p t f A$, fimA, hsf-1, tonB, hgbA, hgbB, Fur, \\
& $\operatorname{nanB}$, nanH, pmHAS, ompA, oomph, oma87, \\
& plpB, soda, sodC, tbpA
\end{tabular}

$4 \quad$ Type D ptfA, hsf-2, pfhA, exbB, exbD, hgbA, hgbB,
Fur, nanB, nanH, ompA, oomph, oma87, plpB, sodC, tbp A

\begin{aligned} \hline Type D & ptfA, fimA, hsf-2, pfhA, tadD, exbB, hgbA, \\ & hgbB, Fur, nanB, nanH, ompA, oomph, \\ & oma87, plpB, sodC \end{aligned}

\begin{tabular}{lll}
\hline 6 & Untyped & $\begin{array}{l}\text { pfhA, Fur, nanB, nanH, ompA, oomph, } \\
\text { oma87, plpB, tbpA }\end{array}$ \\
\hline 7 & Type A & ptfA, fimA, hsf-1, hsf-2, toxA, exbD, tonB,
\end{tabular}

\begin{tabular}{ll} 
& hgbA, hgbB, Fur, nanB, nanH, pmHAS, \\
& ompA, oomph, oma87, plpB, sodA, sodC \\
\hline Type A $\quad$ & ptfA, fimA, hsf-1, hsf-2, pfhA, exbB, exbD, \\
& tonB, hgbA, hgbB, Fur, nanB, nanH, pmHAS, \\
& ompA, oomph, oma87, plpB, soda, sodC, \\
& tbpA
\end{tabular}

\begin{tabular}{ll}
\hline Type A & ptfA, fimA, hsf-1, hsf-2, pfhA, exbB, exbD, \\
& tonB, hgbA, hgbB, Fur, nanB, pmHAS, plpB, \\
& ompA, oomph, oma87, soda, sodC, tbpA
\end{tabular}

\begin{tabular}{ll}
\hline $10 \quad$ Type A & ptfA, fimA, exbB, exbD, tonB, hgbA, hgbB, \\
& Fur, nanB, pmHAS, ompA, oma87, plpB, \\
& soda, sodC, tbpA \\
\hline
\end{tabular}

\begin{tabular}{ll}
\hline $11 \quad$ Type D & ptfA, fimA, hsf-2, pfhA, exbB, exbD, hgbA, \\
& hgbB, Fur, nanB, nanH, pmHAS, ompA, \\
& oma87, plpB
\end{tabular}

\begin{tabular}{lll}
\hline 12 & Type A & $\begin{array}{l}\text { ptfA, fimA, hsf-2, exbB, exbD, tonB, hgbA, } \\
\text { hgbB, pmHAS, oma87, plpB, soda, sodC }\end{array}$ \\
\hline 13 & Type A & ptfA, fimA, hsf-1, hsf-2, pfhA, tadD, exbB,
\end{tabular}
exbD, tonB, hgbA, hgbB, Fur, nanB, ompA, oomph, oma87, plpB, soda, sodC, tbpA

\begin{tabular}{lll}
\hline 14 & Type A & ptfA, fimA, hsf-1, hsf-2, pfhA, tadD, exbB, \\
& exbD, tonB, hgbA, hgbB, Fur, nanB, ompA, \\
& oomph, oma87, plpB, sodA, sodC, tbpA \\
\hline $15 \quad$ Type A & ptfA, fimA, hsf-1, hsf-2, exbB, exbD, tonB, \\
& hgbA, hgbB, Fur, nanB, nanH, ompA, \\
& oomph, oma87, plpB, soda, sodC, tbpA
\end{tabular}

\section{Table 6 | Continued}

\begin{tabular}{|c|c|c|}
\hline Strain ID & Capsule type & Virulence genes \\
\hline 16 & Type D & $\begin{array}{l}\text { ptfA, fimA, hsf-2, tadD, exbB, exbD, hgbA, } \\
\text { hgbB, Fur, nanB, nanH, pmHAS, ompA, } \\
\text { oomph, oma87, plpB, sodA }\end{array}$ \\
\hline 17 & Type A & $\begin{array}{l}\text { ptfA, fimA, hsf-2, tadD, exbB, exbD, tonB, } \\
\text { hgbB, Fur, nanB, nanH, ompA, oomph, } \\
\text { oma87, plpB, soda, sodC, tbp } A\end{array}$ \\
\hline 18 & Type A & $\begin{array}{l}\text { ptfA, fimA, hsf-1, pfhA, toxA, exbB, exbD, } \\
\text { tonB, hgbB, Fur, nanB, nanH, ompA, oomph, } \\
\text { oma87, plpB, soda, sodC, tbp } A\end{array}$ \\
\hline
\end{tabular}

19 Type A ptfA, fimA, hsf-1, hsf-2, pfhA, tadD, exbB, exbD, tonB, hgbB, Fur, nanB, nanH, ompA, oomph, oma87, plpB, soda, sodC, tbpA

\begin{tabular}{ll}
\hline Type $A$ & ptfA, fimA, hsf-1, hsf-2, toxA, exbB, exbD, \\
& $\operatorname{ton} B$, hgbA, hgbB, Fur, $\operatorname{nan} B, \operatorname{nanH}$, ompA, \\
& oomph, oma87, soda, sodC, tbpA
\end{tabular}

$21 \quad$ Untyped
$\quad \operatorname{pim} A$, exbB, hgbA, nanH, ompA, oomph,

\begin{tabular}{|c|c|c|}
\hline 22 & Type A & $\begin{array}{l}\text { ptfA, fimA, hsf-1, hsf-2, pfhA, exbB, exbD, } \\
\text { tonB, hgbA, hgbB, Fur, nanB, nanH, ompA, } \\
\text { oomph, oma87, plpB, soda, sodC, tbpA }\end{array}$ \\
\hline 23 & Type A & $\begin{array}{l}\text { ptfA, fimA, hsf-2, exbB, exbD, tonB, hgbA, } \\
\text { hgbB, Fur, nanB, nanH, ompA, oomph, } \\
\text { oma87, plpB, soda, sodC, tbp } A\end{array}$ \\
\hline
\end{tabular}

\begin{tabular}{|c|c|c|}
\hline 24 & Type A & $\begin{array}{l}\text { ptfA, fimA, hsf-2, pfhA, tadD, exbB, exbD, } \\
\text { tonB, hgbA, hgbB, nanB, nanH, ompA, } \\
\text { oomph, oma87, plpB, soda, sodC, tbpA }\end{array}$ \\
\hline 25 & Type A & $\begin{array}{l}\text { ptfA, fimA, hsf-1, hsf-2, pfhA, tadD, exbB, } \\
\text { tonB, hgbA, hgbB, Fur, nanB, nanH, oomph, } \\
\text { oma87, plpB, soda, sodC, tbpA }\end{array}$ \\
\hline
\end{tabular}

\begin{tabular}{lll}
\hline 26 & Type D & $\begin{array}{l}\text { ptfA, hsf-2, pfhA, exbB, hgbA, hgbB, nanB, } \\
\end{array}$ \\
& Fur, ompA, oma87, plpB, soda, sodC \\
\hline 27 & Type A & $\begin{array}{l}\text { hsf-1, hsf-2, pfhA, tadD, exbB, exbD, tonB, } \\
\text { hgbA, hgbB, Fur, nanB, nanH, ompA, } \\
\text { oomph, oma87, soda, sodC, tbpA }\end{array}$ \\
& & fimA, hsf-1, hsf-2, pfhA, tadD, exbB, exbD, \\
& tonB, hgbA, hgbB, Fur, nanH, oomph, \\
& oma87, soda, sodC, tbpA
\end{tabular}

\begin{tabular}{ll}
\hline $29 \quad$ Type A & $h s f-1, h s f-2, \operatorname{pfh} A, \operatorname{tad} D, \operatorname{exbB}, \operatorname{exbD}, \operatorname{ton} B$, \\
& $h g b A$, hgbB, ompA, nanH, oomph, soda, \\
& sodC, tbpA
\end{tabular}

30 Type A hsf-1, hsf-2, pfhA, tadD, exbB, exbD, tonB, hgbA, hgbB, nanH, ompA, oomph, oma87, soda, sodC 
Table 7 | Distribution of VFs according to associated VF genes.

\begin{tabular}{|c|c|c|c|}
\hline $\begin{array}{l}\text { Virulence } \\
\text { genes }\end{array}$ & $\begin{array}{c}\text { Overall } \\
\text { prevalence } \\
(n=30)\end{array}$ & $\begin{array}{l}\text { Pneumonic lung } \\
\text { isolates } \\
(n=25)\end{array}$ & $\begin{array}{l}\text { Apparently healthy } \\
\text { lung isolates } \\
(n=5)\end{array}$ \\
\hline \multicolumn{4}{|c|}{ ADHESINS } \\
\hline ptfA & $24(80.0 \%)$ & $23(92.0 \%)$ & $1(20.0 \%)$ \\
\hline $\operatorname{fim} A$ & $24(80.0 \%)$ & $23(92.0 \%)$ & $1(20.0 \%)$ \\
\hline$h s f-1$ & $18(60.0 \%)$ & $18(72.0 \%)$ & - \\
\hline hsf-2 & $23(76.7 \%)$ & $23(92.0 \%)$ & - \\
\hline pfhA & $18(60.0 \%)$ & $15(60.0 \%)$ & $3(60.0 \%)$ \\
\hline $\operatorname{tad} D$ & $12(40.0 \%)$ & $12(48.0 \%)$ & - \\
\hline \multicolumn{4}{|l|}{ TOXINS } \\
\hline toxA & $3(10.0 \%)$ & $3(12.0 \%)$ & - \\
\hline \multicolumn{4}{|c|}{ IRON ACQUISITION } \\
\hline$e x b B$ & $25(83.3 \%)$ & $24(96.0 \%)$ & $1(20.0 \%)$ \\
\hline$e x b D$ & $26(86.7 \%)$ & $25(100.0 \%)$ & $1(20.0 \%)$ \\
\hline $\operatorname{ton} B$ & $25(83.3 \%)$ & $24(96.0 \%)$ & $1(20.0 \%)$ \\
\hline$h g b A$ & $26(86.7 \%)$ & $25(100.0 \%)$ & $1(20.0 \%)$ \\
\hline$h g b B$ & $28(93.3 \%)$ & $25(100.0 \%)$ & $3(60.0 \%)$ \\
\hline Fur & $25(83.3 \%)$ & $24(96.0 \%)$ & $1(20.0 \%)$ \\
\hline \multicolumn{4}{|c|}{ SIALIDASES nanB } \\
\hline $\operatorname{nan} B$ & $25(83.3 \%)$ & $25(100.0 \%)$ & - \\
\hline nanH & $24(80.0 \%)$ & $24(96.0 \%)$ & - \\
\hline \multicolumn{4}{|c|}{ HYALURONIDASE } \\
\hline pmHAS & $10(33.3 \%)$ & $10(40.0 \%)$ & - \\
\hline \multicolumn{4}{|c|}{ PROTECTINS } \\
\hline ompA & $27(90.0 \%)$ & $25(100.0 \%)$ & $2(40.0 \%)$ \\
\hline ompH & $26(86.7 \%)$ & $25(100.0 \%)$ & $1(20.0 \%)$ \\
\hline oma87 & $27(90.0 \%)$ & $25(100.0 \%)$ & $2(40.0 \%)$ \\
\hline$p / p B$ & $25(83.3 \%)$ & $24(96.0 \%)$ & $1(20.0 \%)$ \\
\hline \multicolumn{4}{|c|}{ SUPEROXIDE DISMUTASE } \\
\hline sodA & $25(83.3 \%)$ & $24(96.0 \%)$ & $1(20.0 \%)$ \\
\hline sodC & $26(86.7 \%)$ & $25(100.0 \%)$ & $1(20.0 \%)$ \\
\hline tbpA & $20(66.7 \%)$ & $18(72.0 \%)$ & $2(40.0 \%)$ \\
\hline
\end{tabular}

4/46) of this gene in a study conducted on rabbits. Variable frequencies of the genes encoding proteins with different functions, such as adhesins (fimA, hsf-1, hsf-2, and pfhA), iron acquisition (exbB, exbD, tonB, hgbA, hgbB, and Fur), sialidases (nanB and nanH), hyaluronidase (pmHAS), and protectins (oomph and $\mathrm{plpB}$ ) were found in the isolates. This finding is similar to what was reported in previous works which involved ruminants, porcine, poultry, and rabbits (Ewers et al., 2006; Tang et al., 2009; Ferreira et al., 2012).

Infections with P. multocida are commonly managed by broadspectrum antimicrobials (Kehrenberg et al., 2001; Lion et al., 2006; Brogden et al., 2007). Studies have however reported occurrence of resistance to a large number of antimicrobial agents among P. multocida isolates (Hunt et al., 2001; Davies et al., 2004; Arashima and Kumasaka, 2005). In the current study all the $P$. multocida isolates were susceptible to ciprofloxacin, co-trimoxazole, doxycycline, enrofloxacin, nitrofurantoin, and tetracyclines. Similar observations for ciprofloxacin and cotrimoxazole (Mohamed et al., 2012); and for enrofloxacin, tetracycline, and doxycycline (Ferreira et al., 2012) have also
Table 8 | Distribution of VFs according to capsule serotypes among 30 bovine isolates of $P$ multocida.

\begin{tabular}{|c|c|c|c|c|}
\hline $\begin{array}{l}\text { Virulence } \\
\text { genes }\end{array}$ & $\begin{array}{l}\text { Overall } \\
(n=30)\end{array}$ & $\begin{array}{c}\text { capA } \\
(n=23)\end{array}$ & $\begin{array}{c}\text { capD } \\
(n=5)\end{array}$ & $\begin{array}{l}\text { Untyped } \\
(n=2)\end{array}$ \\
\hline \multicolumn{5}{|c|}{ ADHESINS } \\
\hline ptfA & $24(80.0 \%)$ & $19(82.6 \%)$ & $5(100.0 \%)$ & - \\
\hline $\operatorname{fim} A$ & $24(80.0 \%)$ & $20(87.0 \%)$ & $3(60.0 \%)$ & $1(50.0 \%)$ \\
\hline$h s f-1$ & $18(60.0 \%)$ & $18(78.3 \%)$ & - & - \\
\hline hsf-2 & $23(76.7 \%)$ & $18(78.3 \%)$ & $5(100.0 \%)$ & - \\
\hline$p f h A$ & $18(60.0 \%)$ & $13(56.5 \%)$ & $4(80.0 \%)$ & $1(50.0 \%)$ \\
\hline $\operatorname{tad} D$ & $12(40.0 \%)$ & $10(43.5 \%)$ & $2(40.0 \%)$ & - \\
\hline \multicolumn{5}{|l|}{ TOXINS } \\
\hline tox $A$ & $3(10.0 \%)$ & $3(13.0 \%)$ & - & - \\
\hline \multicolumn{5}{|c|}{ IRON ACQUISITION } \\
\hline$e x b B$ & $25(83.3 \%)$ & $19(82.6 \%)$ & $5(100.0 \%)$ & $1(50.0 \%)$ \\
\hline exbD & $26(86.7 \%)$ & $23(100.0 \%)$ & $3(60.0 \%)$ & - \\
\hline $\operatorname{ton} B$ & $25(83.3 \%)$ & $23(100.0 \%)$ & - & $2(100.0 \%)$ \\
\hline$h g b A$ & $26(86.7 \%)$ & $20(87.0 \%)$ & $5(100.0 \%)$ & $1(50.0 \%)$ \\
\hline$h g b B$ & $28(93.3 \%)$ & $23(100.0 \%)$ & $5(100.0 \%)$ & - \\
\hline Fur & $25(83.3 \%)$ & $19(82.6 \%)$ & $5(100.0 \%)$ & $1(50.0 \%)$ \\
\hline \multicolumn{5}{|c|}{ SIALIDASES nanB } \\
\hline nanB & $25(83.3 \%)$ & $19(82.6 \%)$ & $5(100.0 \%)$ & $1(50.0 \%)$ \\
\hline nanH & $24(80.0 \%)$ & $18(78.3 \%)$ & $4(80.0 \%)$ & $2(100.0 \%)$ \\
\hline \multicolumn{5}{|c|}{ HYALURONIDASE } \\
\hline pmHAS & $10(33.3 \%)$ & $8(34.8 \%)$ & $2(40.0 \%)$ & - \\
\hline \multicolumn{5}{|c|}{ PROTECTINS } \\
\hline ompA & $27(90.0 \%)$ & $20(87.0 \%)$ & $5(100.0 \%)$ & $2(100.0 \%)$ \\
\hline $\mathrm{ompH}$ & $26(86.7 \%)$ & $21(91.3 \%)$ & $3(60.0 \%)$ & $2(100.0 \%)$ \\
\hline oma87 & $27(90.0 \%)$ & $21(91.3 \%)$ & $5(100.0 \%)$ & $1(50.0 \%)$ \\
\hline$p / p B$ & $25(83.3 \%)$ & $18(78.3 \%)$ & $5(100.0 \%)$ & $2(100.0 \%)$ \\
\hline \multicolumn{5}{|c|}{ SUPEROXIDE DISMUTASE } \\
\hline sodA & $25(83.3 \%)$ & $23(100.0 \%)$ & $2(40.0 \%)$ & - \\
\hline sodC & $26(86.7 \%)$ & $23(100.0 \%)$ & $3(60.0 \%)$ & - \\
\hline tbpA & $20(66.7 \%)$ & $18(78.3 \%)$ & $1(20.0 \%)$ & $1(50.0 \%)$ \\
\hline
\end{tabular}

been made earlier. These antibiotics can therefore be used for prevention and treatment of bovine P. multocida infections in the study area. Unlike other authors who reported poor (Gutiérrez Martin and Rodríguez Ferri, 1993; Yoshimura et al., 2001) and moderate (Mohamed et al., 2012) activity of aminoglycoside antibiotics against $P$. multocida, in the present study kanamycin, gentamicin, amikacin, and streptomycin exhibited high activity against the tested isolates. The frequencies of resistant isolates to other antibiotics varied greatly as reported by other researchers (Salmon et al., 1995; Kehrenberg et al., 2001; Yoshimura et al., 2001; Welsh et al., 2004).

The major limitation in the discussion of the findings of the current study was large differences in the sample sizes of comparison groups as seen for isolates between isolates from pneumonic lungs and those from apparently health lungs; and isolates of different capsular types. This made it difficult to infer on the observed variations as they could be attributed to chance.

In summary, our results reveal presence of VFs in P. multocida strains isolated from the lungs of symptomatic and asymptomatic 
Table 9 | Antimicrobial resistance profiles of $P$ multocida isolates against 20 antimicrobial agents.

\begin{tabular}{lccc}
\hline Antimicrobial & $\begin{array}{c}\text { Resistant } \\
\text { isolates }\end{array}$ & $\begin{array}{c}\text { Intermediate } \\
\text { resistant isolates }\end{array}$ & $\begin{array}{c}\text { Susceptible } \\
\text { isolates }\end{array}$ \\
\hline Ampicillin & $10(33.3 \%)$ & $11(36.7 \%)$ & $9(30.0 \%)$ \\
Amikacin & $0(0.0 \%)$ & $1(3.3 \%)$ & $29(96.7 \%)$ \\
Cloramphenicol & $0(0.0 \%)$ & $0(0.0 \%)$ & $29(96.7 \%)$ \\
Carbenicillin & $0(0.0 \%)$ & $1(3.3 \%)$ & $29(96.7 \%)$ \\
Ciprofloxacin & $0(0.0 \%)$ & $0(0.0 \%)$ & $30(100.0 \%)$ \\
Co-trimoxazole & $0(0.0 \%)$ & $0(0.0 \%)$ & $30(100.0 \%)$ \\
Doxycycline & $0(0.0 \%)$ & $0(0.0 \%)$ & $30(100.0 \%)$ \\
Enrofloxacin & $0(0.0 \%)$ & $0(0.0 \%)$ & $30(100.0 \%)$ \\
Gentamicin & $0(0.0 \%)$ & $1(3.3 \%)$ & $29(96.7 \%)$ \\
Lincomycin & $13(43.3 \%)$ & $8(26.7 \%)$ & $8(26.7 \%)$ \\
Nitrofurantoin & $0(0.0 \%)$ & $0(0.0 \%)$ & $30(100.0 \%)$ \\
Oxytetracycline & $0(0.0 \%)$ & $0(0.0 \%)$ & $30(100.0 \%)$ \\
Penicillin & $12(40.0 \%)$ & $9(30.0 \%)$ & $9(30.0 \%)$ \\
Rifampin & $6(20.0 \%)$ & $6(20.0 \%)$ & $18(60.0 \%)$ \\
Streptomycin & $5(16.7 \%)$ & $0(0.0 \%)$ & $25(83.3 \%)$ \\
Tetracycline & $0(0.0 \%)$ & $0(0.0 \%)$ & $30(100.0 \%)$ \\
Amoxicillin & $3(10.0 \%)$ & $3(10.0 \%)$ & $24(80.0 \%)$ \\
Erythromycin & $10(33.3 \%)$ & $10(33.3 \%)$ & $10(33.3 \%)$ \\
Kanamycin & $0(0.0 \%)$ & $4(13.3 \%)$ & $26(86.7 \%)$ \\
Florfenicol & $5(16.7 \%)$ & $6(20.0 \%)$ & $19(63.3 \%)$ \\
\hline & $0.04 \%)$ & & \\
\hline
\end{tabular}

slaughter cattle. Frequent detection of the factors among isolates from symptomatic study animals may suggest their role in pathogenesis of BRD caused by these organisms. Occurrence of antimicrobial resistance among some isolates is of great concern. Control strategies for this pathogen, which could include development of an effective vaccine, are warranted so as to mitigate the social and economic consequences attributable to natural infections with this bacterium. Further, the use of antimicrobial agents in modern livestock farming need to be controlled so as to minimize the emergence and eventually spread of resistance not only in target microbes but also in other important zoonotic pathogens.

\section{ACKNOWLEDGMENTS}

The authors would like to acknowledge the valuable contribution of Dr. Erick V. G. Komba of the Department of Veterinary Medicine and Public Health of Sokoine University of Agriculture, Morogoro, Tanzania; for reviewing this work before submission to the journal. Also the authors would like to thank Mr. M. Momeni at the Biotechnology Research Center of the Islamic Azad University of Shahrekord for technical support.

\section{REFERENCES}

Arashima, Y., and Kumasaka, K. (2005). Pasteurellosis as zoonosis. Intern. Med. 44, 692-693. doi: 10.2169/internalmedicine.44.692

Arumugam, N. D., Ajam, N., Blackall, P. J., Asiah, N. M., Ramlan, M., Maria, J., et al. (2011). Capsular serotyping of Pasteurella multocida from various animal hosts-a comparison of phenotypic and genotypic methods. Trop. Biomed. 28, 55-63.

Atashpaz, S., Shayegh, J., and Hejazi, M. S. (2009). Rapid virulence typing of Pasteurella multocida by multiplex PCR. Res. Vet. Sci. 87, 355-357. doi: 10.1016/j.rvsc.2009.04.004
Brogden, K. A., Nordholm, G., and Ackermann, M. (2007). Antimicrobial activity of cathelicidins BMAP28, SMAP28, SMAP29, and PMAP23 against Pasteurella multocida is more broad-spectrum than host species specific. Vet. Microbiol. 119, 76-81. doi: 10.1016/j.vetmic.2006.08.005

Caprioli, A., Busani, L., Martel, J. L., and Helmuth, R. (2000). Monitoring of antibiotic resistance in bacteria of animal origin: epidemiological and microbiological methodologies. Int. J. Antimicrob. Agents 14, 295-301. doi: 10.1016/S09248579(00)00140-0

Carter, G. R. (1955). Studies on Pasteurella multocida. A hemagglutination test for the identification of serological types. Am. J. Vet. Res. 16, 481-484.

Carter, G. R. (1961). A new serological type of Pasteurella multocida from Central Africa. Vet. Rec. 73, 1052.

Carter, G. R. (1967). Pasteurellosis: Pasteurella multocida and Pasteurella hemolytica. Adv. Vet. Sci. 11, 321-379.

Carter, G. R., and Subronto, P. (1978). Identification of type D strains of Pasteurella multocida with acriflavin. Am. J. Vet. Res. 34, 348-352.

Confer, A. W. (2009). Update on bacterial pathogenesis in BRD. Anim. Health Res. Rev. 10, 145-148. doi: 10.1017/S1466252309990193

Dabo, S. M., Taylor, J. D., and Confer, A. W. (2007). Pasteurella multocida and bovine respiratory disease. Anim. Health Res. Rev. 8, 129-150. doi: 10.1017/S1466252307001399

Dagleish, M. P., Finlayson, J., Bayne, C., MacDonald, S., Sales, J., and Hodgson, J. C. (2010). Characterization and time course of pulmonary lesions in calves after Intratracheal infection with Pasteurella multocida A:3. J. Comp. Pathol. 142, 157-169. doi: 10.1016/j.jcpa.2009.10.015

Davies, R. L., MacCorquodale, R., and Reilly, S. (2004). Characterisation of bovine strains of Pasteurella multocida and comparison with isolates of avian, ovine and porcine origin. Vet. Microbiol. 99, 145-158. doi: 10.1016/j.vetmic.2003. 11.013

Griffin, D., Chengappa, M. M., Kuszak, J., and McVey, D. S. (2010). Bacterial pathogens of the bovine respiratory disease complex. Vet. Clin. North Am. Food Anim. Pract. 26, 381-394. doi: 10.1016/j.cvfa.2010.04.004

Ewers, C., Lübke-Becker, A., Bethe, A., Kiebling, S., Filter, M., and Wieler, L. H. (2000). Virulence genotype of Pasteurella multocida strains isolated from different hosts with various disease status. Vet. Microbiol. 114, 304-317. doi: 10.1016/j.vetmic.2005.12.012

Ewers, C., Lübke-Becker, A., Bethe, A., Kiebling, S., Filter, M., and Wieler, L. H. (2006). Virulence genotype of Pasteurella multocida strains isolated from different hosts with various disease status. Vet. Microbiol. 114, 304-317. doi: 10.1016/j.vetmic.2005.12.012

Ewers, C., Lübke-Becker, A., and Wieler, L. H. (2004). Pasteurella: insights into the virulence determinants of a heterogenous bacterial type. Berliner und Münchener Tierärztliche Wochenschrift 117, 367-386.

Ferreira, T. S., Felizardo, M. R., Sena de Gobbi, D. D., Gomes, C. R., Nogueira Filsner, P. H., Moreno, M., et al. (2012). Virulence genes and antimicrobial resistance profiles of Pasteurella multocida strains isolated from rabbits in Brazil. Sci. World J. 2012:685028. doi: 10.1100/2012/685028

García, N., Fernández-Garayzábal, J. F., Goyache, J., Domínguez, L., and Vela, A. I. (2011). Associations between biovar and virulence factor genes in Pasteurella multocida isolates from pigs in Spain. Vet. Rec. 169, 362. doi: 10.1136/ vr.d4869

Gutiérrez Martin, C. B., and Rodríguez Ferri, E. F. (1993). In vitro susceptibility of Pasteurella multocida subspecies multocida strains isolated from swine to 42 antimicrobial agents. Zentralbl. Bakteriol. 279, 387-393.

Haji Hajikolaei, M. R., Ghorbanpour, M., Seyfiabad Shapouri, M. R., Rasooli, A., Ebrahimkhani, D., and Jabbari, A. R. (2010). Bacteriological and serological studies on Mannheimia haemolytica infection in cattle slaughtered at Ahvaz (southwestern Iran) abattoir. J. Vet. Res. 11, 84-87.

Haji Hajikolaei, M. R., and Seyfi Abad Shapouri, M. R. (2007). Serological study of bovine diarrhea virus infection of cattle in Ahvaz. J. Vet. Res. 62, 21-26.

Harper, M., Boyce, J. D., and Adler, B. (2006). Pasteurella multocida pathogenesis: 125 years after Pasteur. FEMS Microbiol. Lett. 265, 1-10. doi: 10.1111/j.15746968.2006.00442.x

Hatfaludi, T., Al-Hasani, K., Boyce, J. D., and Adler, B. (2010). Outer membrane proteins of Pasteurella multocida. Vet. Microbiol. 14, 1-17. doi: 10.1016/j.vetmic.2010.01.027

Hemmatzadeh, F., Kojouri, G., Kargar Moakhar, R., and Rohany, M. (2001). A serological survey on bovine viral diarrhea virus infection in Chahar Mahal Bakhtiary province, Iran. J. Fac. Vet. Med. Univ. Tehran 56, 85-92. 
Hotchkiss, E. J., Dagleish, M. P., Willoughby, K., McKendrick, I. J., Finlayson, J., Zadoks, R. N., et al. (2010). Prevalence of Pasteurella multocida and other respiratory pathogens in thenasal tract of Scottish calves. Vet. Rec. 167, 555-560. doi: 10.1136/vr.c4827

Hubbert, W. T., and Rosen, M. N. (1970). Pasteurella multocida infections. II: Pasteurella multocida infection in man unrelated to animal bite. Am. J. Public Health Nations Health 60, 1109-1117. doi: 10.2105/AJPH.60.6.1109

Hunt, M. L., Adler, B., and Townsend, K. M. (2000). The molecular biology of Pasteurella multocida. Vet. Microbiol. 72, 3-25. doi: 10.1016/S03781135(99)00183-2

Hunt, M. L., Boucher, D. J., Boyce, J. D., and Adler, B. (2001). In vivoexpressed genes of Pasteurella multocida. Infect. Immun. 69, 3004-3012. doi: 10.1128/IAI.69.5.3004-3012.2001

Katoch, S., Sharma, M., Patil, R. D., Kumar, S., and Verma, S. (2014). In vitro and in vivo pathogenicity studies of Pasteurella multocida strains harbouring different ompA. Vet. Res. Commun. 38, 183-191. doi: 10.1007/s11259-014-9601-6

Katsuda, K., Hoshinoo, K., Ueno, Y., Kohmoto, M., and Mikami, O. (2013). Virulence genes and antimicrobial susceptibility in Pasteurella multocida isolates from calves. Vet. Microbiol. 167, 737-741. doi: 10.1016/j.vetmic.2013. 09.029

Kehrenberg, C., Schulze-Tanzil, G., Martel, J. L., Chaslus-Dancla, E., and Schwarz, S. (2001). Antimicrobial resistance in Pasteurella and Mannheimia: epidemiology and genetic basis. Vet. Res. 32, 323-339. doi: 10.1051/vetres:2001128

Kelly, L., Smith, D. L., Snary, E. L., Johnson, J. A., Harris, A. D., Wooldrige, M., et al. (2004). Animal growth promoters: to ban or not to ban? A risk assessment approach. Int. J. Antimicrob. Agents 24, 205-212. doi: 10.1016/j.ijantimicag.2004.04.007

Kline, K. A., Fälker, S., Dahlberg, S., Normark, S., and Henriques-Normark, B. (2009). Bacterial adhesins in host-microbe interaction. Cell Host Microbe 5, 580-592. doi: 10.1016/j.chom.2009.05.011

Lainson, F. A., Dagleish, M. P., Fontaine, M. C., Bayne, C., and Hodgson, J. C. (2013). Draft genome sequence of Pasteurella multocida A:3 Strain 671/90. Genome Announc. 1, e00803-e00813. doi: 10.1128/genomeA.00803-13

Lainson, F. A., Thomson, N., Rowe, H. A., Langford, P. R., Aitchison, K. D., Donachie, W., et al. (1996). Occurrence of [copper, zinc]-cofactored superoxide dismutase in Pasteurella haemolytica and its serotype distribution. FEMS Microbiol. Lett. 142, 11-17. doi: 10.1111/j.1574-6968.1996.tb08400.x

Levy, S. B. (1998). The challenge of antibiotic resistance. Sci. Am. 278, 46-53. doi: 10.1038/scientificamerican0398-46

Lion, C., Conroy, M. C., Carpentier, A. M., and Lozniewski, A. (2006). Antimicrobial susceptibilities of Pasteurella strains isolated from humans. Int. J. Antimicrob. Agents 27, 290-293. doi: 10.1016/j.ijantimicag.2006.02.004

Mannheim, W. (1984). "Family III. Pasteurellaceae," in Bergey's Manual of Systematic Bacteriology, Vol. 1, eds N. R. Krieg, and J. G. Kolt (Baltimore, MD: Williams \& Wilkins), 550-575.

May, B. J., Zhang, Q., Li, L. L., Paustian, M. L., Whittam, T. S., and Kapur, V. (2001). Complete genomic sequence of Pasteurella multocida, Pm70. Proc. Natl. Acad. Sci. U.S.A. 98, 3460-3465. doi: 10.1073/pnas.051634598

Mohamed, M. A., Mohamed, M. W., Ahmed, A. I., Ibrahim, A. A., and Ahmed, M. S. (2012). Pasteurella multocida in backyard chickens in Upper Egypt: incidence with polymerase chain reaction analysis for capsule type, virulence in chicken embryos and antimicrobial resistance. Vet. Ital. 48, 77-86.

Nanduri, B., Shack, L. A., Burgess, S. C., and Lawrence, M. L. (2009). The transcriptional response of Pasteurella multocida to three classes of antibiotics. BMC Genomics 10:S4 doi: 10.1186/1471-2164-10-S2-S4

National Committee for Clinical Laboratory Standards. (2008). Performance Standards for Antimicrobial Disk and Dilution Susceptibility Tests for Bacteria Isolated from Animals; Approved Standard, 2nd Edn. NCCLS Document M31A3. Wayne, PA: National Committee for Clinical Laboratory Standards.

Portis, E., Lindeman, C., Johansen, L., and Stoltman, G. (2012). A ten-year (2000-2009) study of antimicrobial susceptibility of bacteria that cause bovine respiratory disease complex-Mannheimia haemolytica, Pasteurella multocida, and Histophilus somni-in the United States and Canada. J. Vet. Diagn. Invest. 24, 932-944 doi: 10.1177/1040638712457559

Pullinger, G. D., Bevir, T., and Lax, A. J. (2004). The Pasteurella multocida toxin is encoded within a lysogenic bacteriophage. Mol. Microbiol. 51, 255-269. doi: 10.1046/j.1365-2958.2003.03829.x

Rimler, R. B., and Rhoades, K. R. (1987). Serogroup F, a new capsule serogroup of Pasteurella multocida. J. Clin. Microbiol. 25, 615-618.

Sakhaee, E., Khalili, M., and Kazeminia, S. (2009). Serological study of bovine viral respiratory diseases in dairy herds in Kerman province, Iran. Iran. J. Vet. Res. 10, 49-53.

Salmon, S. A., Watts, J. L., Case, C. A., Hoffman, L. J., Wegener, H. C., and Yancey, R. J. Jr. (1995). Comparison of MICs of ceftiofur and other antimicrobial agents against bacterial pathogens of swine from the United States, Canada, and Denmark. J. Clin. Microbiol. 33, 2435-2444.

Shea, K. M. (2003). Antibiotic resistance. What is the impact of agricultural uses of antibiotics on children health? Pediatrics 112, 253-258.

Songer, J. G., and Post, K. W. (2005). Veterinary Microbiology, Bacterial and Fungal Agents of Animal Diseases. 1st Edn. Saint Louis, MO: Elsevier Saunders.

Steen, J. A., Steen, J. A., Harrison, P., Seemann, T., Wilkie, I., Harper, M., et al. (2010). Fis is essential for capsule production in Pasteurella multocida and regulates expression of other important virulence factors. PLOS Pathog. 6:e1000750. doi: 10.1371/journal.ppat.1000750

Tang, X., Zhao, Z., Hu, J., Wu, B., Cai, X., He, Q., et al. (2009). Isolation, antimicrobialm resistance, and virulence genes of Pasteurella multocida strains from swine in China. J. Clin. Microbiol. 47, 951-958. doi: 10.1128/JCM.02029-08

Townsend, K. M., Frost, A. J., Lee, C. W., Papadimitriou, J. M., and Dawkins, H. J. S. (1998). Development of PCR assays for species and type-specific identification of Pasteurella multocida isolates. J. Clin. Microbiol. 36, 1096-1100.

Verma, S., Sharma, M., Katoch, S., Verma, L., Kumar, S., Dogra, V., et al. (2013). Profiling of virulence associated genes of Pasteurella multocida isolated from cattle. Vet. Res. Commun. 37, 83-89. doi: 10.1007/s11259-012-9539-5

Welsh, R. D., Dye, L. B., Payton, M. E., and Confer, A. W. (2004). Isolation and antimicrobial susceptibilities of bacterial pathogens from bovine pneumonia: 1994-2002. J. Vet. Diagn. Invest. 16, 426-431. doi: $10.1177 / 104063870401600510$

White, D. G., Zhao, S., Simjee, S., Wagner, D. D., and McDermott, P. F. (2002). Antimicrobial resistance of foodborne pathogens. Microbes Infect. 4, 405-412. doi: 10.1016/S1286-4579(02)01554-X

Witte, W. (1998). Medical consequences of antibiotic use in agriculture. Science 279, 996-997. doi: 10.1126/science.279.5353.996

Yoshimura, H., Ishimaru, M., Endoh, Y. S., and Kojima, A. (2001). Antimicrobial susceptibility of Pasteurella multocida isolated from cattle and pigs. J. Vet. Med. B Infect. Dis. Vet. Public Health 48, 555-560. doi: 10.1046/j.14390450.2001.00468.x

Conflict of Interest Statement: The authors declare that the research was conducted in the absence of any commercial or financial relationships that could be construed as a potential conflict of interest.

Received: 18 June 2014; accepted: 26 September 2014; published online: 14 October 2014.

Citation: Khamesipour F, Momtaz H and Azhdary Mamoreh M (2014) Occurrence of virulence factors and antimicrobial resistance in Pasteurella multocida strains isolated from slaughter cattle in Iran. Front. Microbiol. 5:536. doi: 10.3389/fmicb.2014.00536 This article was submitted to Infectious Diseases, a section of the journal Frontiers in Microbiology.

Copyright (C) 2014 Khamesipour, Momtaz and Azhdary Mamoreh. This is an openaccess article distributed under the terms of the Creative Commons Attribution License (CC BY). The use, distribution or reproduction in other forums is permitted, provided the original author(s) or licensor are credited and that the original publication in this journal is cited, in accordance with accepted academic practice. No use, distribution or reproduction is permitted which does not comply with these terms. 